\title{
Allergy to laboratory animals: a prospective study of its incidence and of the influence of atopy on its development
}

\author{
P A BOTHAM, ${ }^{1}$ G E DAVIES, ${ }^{1}$ E L TEASDALE ${ }^{2}$ \\ From the Central Toxicology Laboratory, ${ }^{1}$ and Pharmaceuticals Division, ${ }^{2}$ Imperial Chemical Industries plc, \\ Alderley Park, Nr Macclesfield, Cheshire SK10 4TJ, UK
}

ABSTRACT The pattern of incidence of allergy to laboratory animals (ALA) has been studied prospectively in 383 individuals occupationally exposed to rodents and to rabbits. The incidence of the disease after one year of exposure to animals fell from $37 \%$ in 1980 and 1981 to $20 \%$ in 1982 , $10 \%$ in 1983 , and $12 \%$ in 1984 . A similar reduction was noted after two and three years of exposure in the 1982 and 1983 cohorts. The reduction in incidence coincided with the introduction of a site order and code of practice for working with animals and an education programme designed to focus awareness on the problem. Although rats were believed to be the major cause of the disease, objective measurements of IgE antibody against rat urine allergen were positive in only half the symptomatic individuals. Antibodies to different animal derived allergens were, however, found in several other personnel. Symptoms were generally of mild or moderate intensity and affected mainly the nose, eyes, and skin; chest symptoms were found in only $1.6 \%$ of the exposed population. A study of the influence of atopy on the development of ALA showed that after one year of exposure to animals a significantly greater proportion of atopic individuals became symptomatic (19-43\% compared with 3-6\%). After two and three years of exposure, however, this discrepancy was not maintained, with more non-atopic individuals developing the disease.

One of the major risks to the health of animal handlers and scientists working with laboratory animals is the development of respiratory allergy. Surveys conducted at various research establishments between 1974 and 1981 indicated that the prevalence of allergy to laboratory animals (ALA) was between $10 \%$ and $30 \% .^{1-13}$ All the surveys on ALA except for that of Davies et $a^{12}$ have been cross sectional, and the actual incidence of the disease could have been higher than the prevalence figures suggested because "survivor" populations were studied.

The prevalence of asthma as a symptom of ALA, which is now a prescribed industrial disease, was between $3 \%$ and $11 \% .^{25-913}$ Several of the studies suggested that those with asthma were usually atopic (skin test positive to one or more environmental allergens) and usually had skin prick test reactions and

Accepted 1 October 1986 specific circulating IgE antibodies to animal allergens; those with milder symptoms appeared to be no more likely than exposed asymptomatic individuals to be atopic or to have positive skin or blood test reactions. ${ }^{67}$ In addition, it was suggested that most individuals with ALA developed their disease (usually in a mild form) during the first year of exposure to animals, whereas asthma developed in a proportion of these individuals after a longer period of exposure. ${ }^{58}$

The study reported here represents an attempt to investigate ALA prospectively, by examining a group of exposed individuals during their first three years of exposure to animals at the research facilities of ICI at Alderley Park in order to establish the true incidence of the disease and to assess its development.

The two major objectives of this study were:

(1) To establish the pattern of incidence of ALA at Alderley Park, and

(2) To determine whether it is possible to identify at the onset of working with animals those individuals who are predisposed to develop ALA. 


\section{Material and methods}

\section{PREPARATION OF ALLERGENS}

Material was prepared from the urine, epidermis, and serum of rats, mice, guinea pigs, and rabbits by the methods described by Davies et al $^{14}$ and assayed by the ELISA system described. After April 1982, the same material was used to prepare the skin test reagents in place of the previously used reagents described by Davies et al. ${ }^{12}$

\section{ESTIMATION OF SERUM IGE ANTIBODIES}

The modification of the method of Ceska etal ${ }^{15}$ described by Davies et al $^{12}$ was used. IgE antibodies were estimated in all cases only to the rat urine allergen. The remaining 11 allergens were used if either skin prick test results or the reported symptoms so suggested.

\section{SKIN PRICK TESTS}

Skin prick tests were carried out as described previously ${ }^{12}$ using all 12 animal derived allergens. Tests for atopy were carried out using group B2 (pollens) grasses $(2.5 \%)$ and Dermatophagoides pteronyssinus $(1 \cdot 2 \%)$ supplied by Dr Janet Dewdney.

\section{SUBJECTS AND PROCEDURE}

All individuals who entered the company's employment between 1979 and 1984 and who intended to work with animals were invited to enter the survey. All permanent and temporary staff were recruited on to the survey, but those individuals who did not complete a minimum of nine months' service were excluded from the analyses.

Immediately after starting employment each individual completed a questionnaire to determine the nature of any previous contact with animals and to establish whether there was a history of clinical allergic disease. Allergy to animals was not seen then because individuals with a history of ALA were not recruited to work with animals. Skin prick tests were performed and a blood sample was taken for the est mation of IgE antibodies.

One year later, and then annually for a further tw: years (in practice, intervals of 9-15 months elapses between visits because of the administrative difficult of ensuring accurate compliance with regard to inte? view periods), a second questionnaire was completes and skin tests and serum IgE estimates were repeated This second questionnaire detailed the developmeng of any allergic symptoms to animals and the nature and duration of exposure to laboratory animals since the previous interview.

\section{ASSIGNMENT TO COHORTS}

To take account of the possibility of changes over time affecting the incidence of ALA the variable cohort was introduced into the analysis of the data? Thus all individuals who started to work with animaks between 1 January and 31 December 1979 were assigned to the 1979 cohort. Similar assignments were made for the years $1980-4$.

\section{SYMPTOM EVALUATION}

Symptoms reported at the annual interviews we recorded as "nasal" (stuffy or blocked nose, repeatea attacks of sneezing); "eyes" (smarting, itchy); skif (rash, eczema, urticaria); or chest (tightness). Sevefitg was graded as 1 (mild), 2 (moderate), or 3 (severe It should be emphasised that all were subjecei responses on the part of the interviewee. Clinic confirmation was obtained only in certain cases-fö example, when the chest was affected or when the symptoms were a particular nuisance.

\section{Results}

ANNUAL INCIDENCE OF SYMPTOMS

A total of 383 individuals completed at least nine months employment. Table 1 shows the incidence \&f symptoms on an annual basis. After 1981 there wasiat significant and apparently progressive decrease

Table 1 Annual incidence of allergy to laboratory animals

\begin{tabular}{|c|c|c|c|c|c|}
\hline Cohort & Symptom grade & After 1 year & After 2 years & After 3 years & $\stackrel{ }{9}$ \\
\hline 1979 & $\begin{array}{l}\text { Grades } 1-3 \\
\text { Grades 2-3 }\end{array}$ & $\begin{array}{r}14 / 50(28 \%) \\
8 / 50(16 \%)\end{array}$ & $\begin{array}{c}13 / 49(27 \%) \\
4 / 49(8 \%)\end{array}$ & $\begin{array}{c}10 / 46(22 \%) \\
2 / 46(4 \%)\end{array}$ & 三. \\
\hline 1980 & $\begin{array}{l}\text { Grades 1-3 } \\
\text { Grades 2-3 }\end{array}$ & $\begin{array}{r}18 / 49(37 \%) \\
8 / 49(16 \%)\end{array}$ & $\begin{array}{l}20 / 46(43 \%) \\
13 / 46(28 \%)\end{array}$ & $\begin{array}{r}11 / 39(28 \%) \\
7 / 39(18 \%)\end{array}$ & స్ \\
\hline 1981 & $\begin{array}{l}\text { Grades 1-3 } \\
\text { Grades 2-3 }\end{array}$ & $\begin{array}{l}13 / 35(37 \%) \\
13 / 35(37 \%)\end{array}$ & $\begin{array}{l}5 / 19(26 \%) \\
2 / 19(11 \%)\end{array}$ & $\begin{array}{l}5 / 17(29 \%) \\
2 / 17(12 \%)\end{array}$ & \\
\hline 1982 & $\begin{array}{l}\text { Grades 1-3 } \\
\text { Grades 2-3 }\end{array}$ & $\begin{array}{r}14 / 70(20 \%) \\
9 / 70(13 \%)\end{array}$ & $\begin{array}{r}11 / 53(21 \%) \\
6 / 53(11 \%)\end{array}$ & $\begin{array}{l}7 / 37(19 \%) \\
3 / 37(8 \%)\end{array}$ & $\underset{<}{\sigma}$ \\
\hline 1983 & $\begin{array}{l}\text { Grades 1-3 } \\
\text { Grades 2-3 }\end{array}$ & $\begin{array}{c}10 / 98(10 \%) \\
3 / 98(3 \%)\end{array}$ & $\begin{array}{l}8 / 54(15 \%) \\
6 / 54(11 \%)\end{array}$ & & $\frac{\text { C }}{\mathscr{D}}$ \\
\hline 1984 & $\begin{array}{l}\text { Grades 1-3 } \\
\text { Grades } 2-3\end{array}$ & $\begin{array}{c}10 / 81(12 \%) \\
3 / 81(4 \%)\end{array}$ & & & ) \\
\hline
\end{tabular}


incidence of ALA after one year of exposure to animals at Alderley Park, both in symptoms of all grades and of those graded as moderate or severe. By 1983 the incidence of total symptoms had fallen to $10 \%$ compared with the $37 \%$ in 1980 and 1981 , and the improvement was maintained in 1984 with an incidence of $12 \%$. There was also a decrease in incidence after two years of exposure as shown by the 1982 and 1983 cohorts.

In the 1979-82 cohorts two thirds of those individuals who eventually developed ALA did so during their first year of exposure to animals at Alderley Park.

\section{SEVERITY AND CAUSE OF SYMPTOMS}

Five of the 383 individuals developed symptoms that were so severe that they were excluded from working with animals.

The responses of the individuals in the 1982-4 cohorts concerning the species of animal thought to be the cause of their symptoms and the site and severity of the symptoms after one year of exposure are shown in table 2. Rats were the most commonly implicated species, 38 of the total of 51 symptoms being so attributed. Next most common were rabbits with six symptoms attributed and mice with seven. At this time no one thought that guinea pigs caused their symptoms. Nasal symptoms were the commonest, followed by skin, eyes, and then chest.

Only six of the 36 affected individuals reported chest symptoms, representing an overall incidence of $1.6 \%$ after one year of exposure.

\section{INFLUENCE OF ATOPY ON THE DEVELOPMENT OF SYMPTOMS}

In the previous communication reference was made to the relation between "the atopic state" and the development of allergy to laboratory animals. ${ }^{12} \mathrm{We}$ are currently designating as atopic those individuals who gave a positive skin prick test response to grass pollen or to house dust mite of $4 \mathrm{~mm}$ or more. As the skin tests were not carried out on all individuals before 1982 comment will be restricted to those in the 1982 , 1983 , and 1984 cohorts. On entry the respective incidence of atopy in these three cohorts was $45 \%, 30 \%$, and $36 \%$. The corresponding values one year later were $45 \%, 33 \%$, and $36 \%$.

Table 3 shows that after one year of exposure nearly all $(93 \%)$ of the symptomatic subjects in the 1982 cohort were atopic; $42 \%$ of atopic individuals in this cohort developed ALA during the first year whereas only $3 \%$ of non-atopic individuals did so. It must be emphasised, however, that $58 \%$ of atopic subjects did not become allergic to animals. Also worthy of comment is the observation, again in the 1982 cohort, that after two and three years of exposure the proportion of symptomatic subjects who were atopic had fallen to $73 \%$ and $43 \%$ respectively, which might be taken to indicate that atopy predisposes mainly towards the early development of allergy.

The correspondence of symptoms and atopy was less pronounced $(60 \%)$ after one year in the 1983 cohort but had risen again to $80 \%$ by 1984 . As with the 1982 cohort, the 1983 results for two years of exposure showed a pronounced decrease in the proportion of symptomatic subjects who were atopic.

\section{RELATION BETWEEN SYMPTOMS AND \\ IMMUNOLOGY}

All the individuals in the 1982 cohorts were skin tested with the complete range of allergens but IgE estimates are complete only for rat urine allergen, tests for antibodies to the other allergens being carried out only on selected individuals. The relation between symptoms and antibodies to rat urine (as shown by skin test or the presence of circulating $\operatorname{IgE}$ antibody) is shown in table 4. In general the agreement between symptoms and antibody to urine after one year of exposure was unconvincing, being evident in $64 \%, 60 \%$, and $40 \%$, respectively, for the three cohorts. Both estimates (skin and serum) of antibody

Table 2 Severity and cause of symptoms of allergy to laboratory animals after one year of exposure in the 1982-4 cohorts. (Total number of volunteers with symptoms $=36$.)

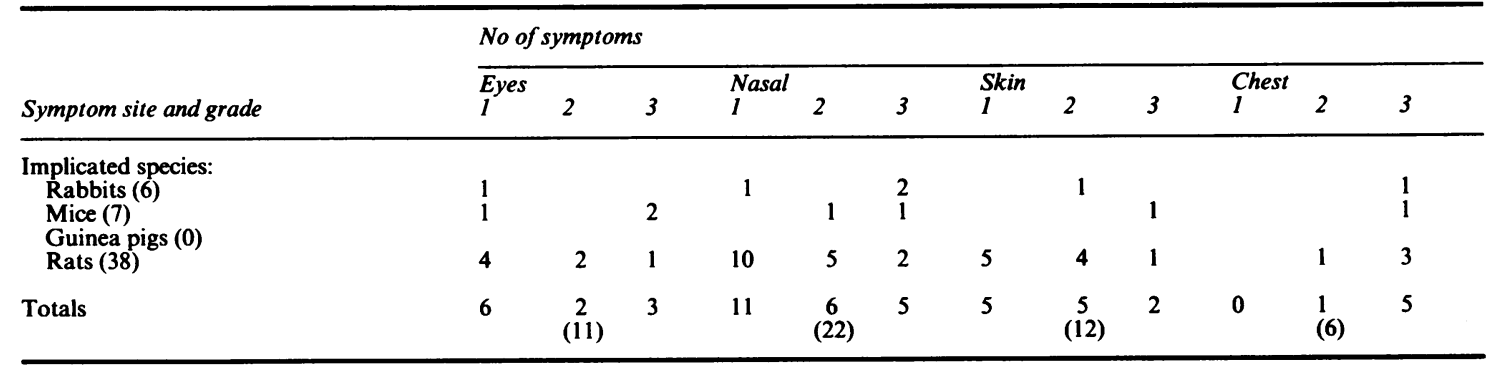


Table 3 Relation between atopy and the development of allergy to laboratory animals

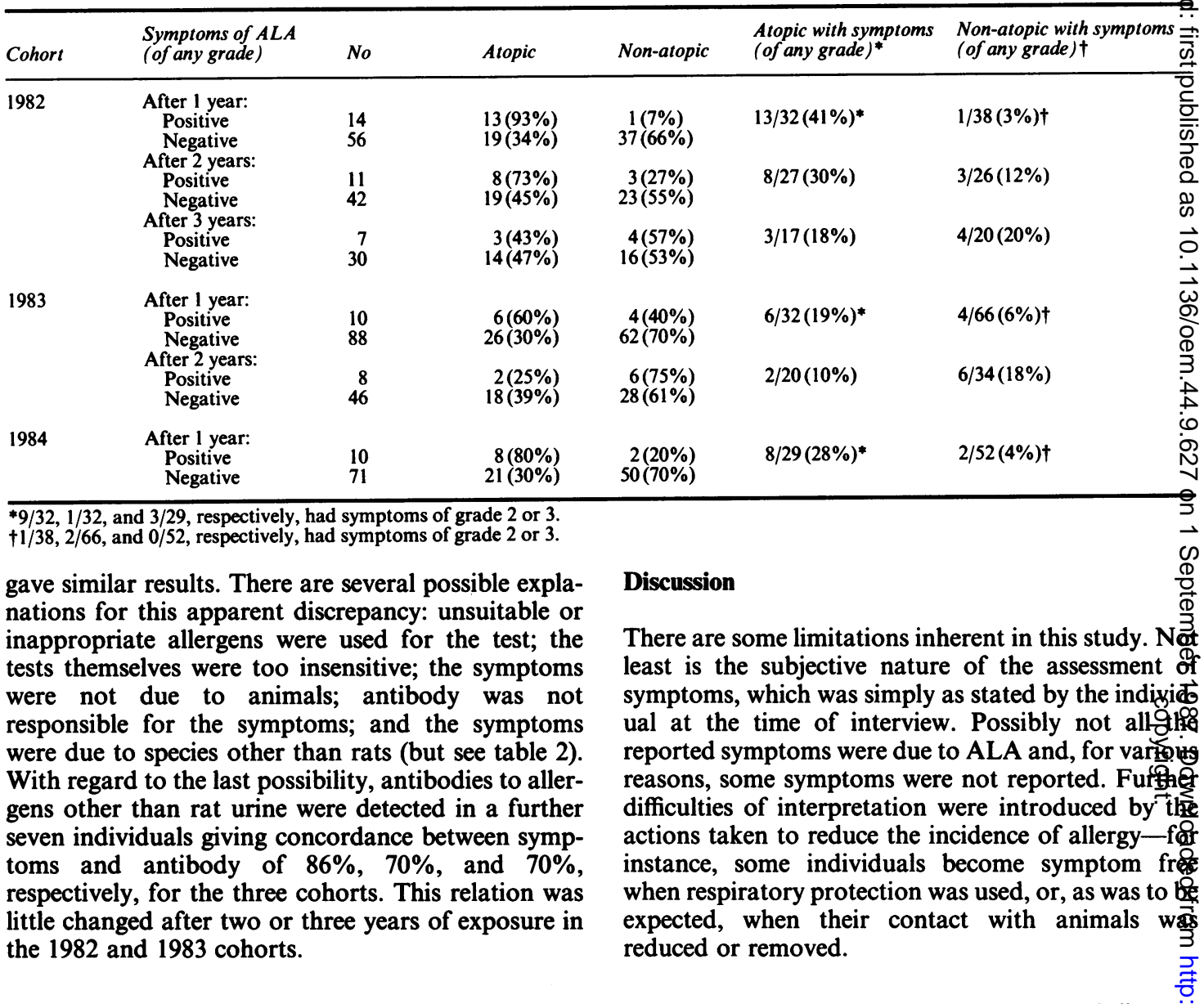

Table 4 Relation between the development of allergy to laboratory animals and the presence of antibodies to animal allergens

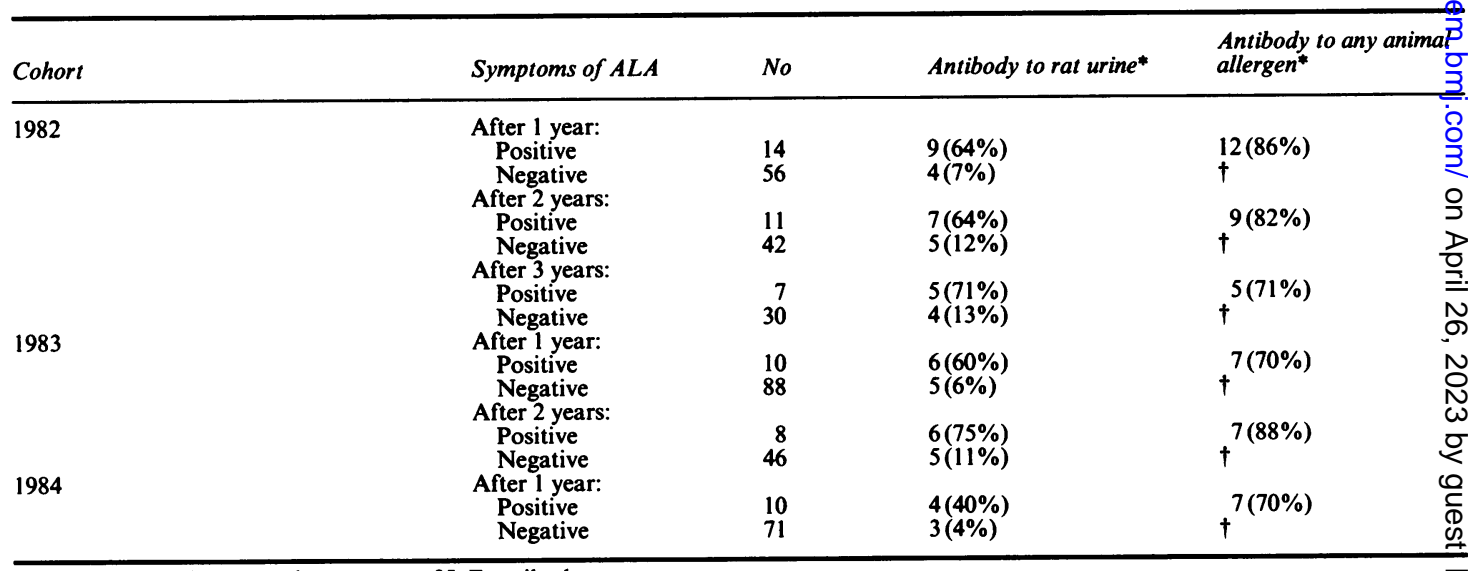

*As shown by skin test or the presence of IgE antibody.

†Data incomplete. 
Nevertheless, a progressive and significant annual decrease in the proportion of individuals reporting symptoms is apparent after 1981 . This coincided with the introduction at Alderley Park of a site order and code of practice for working with animals (the overall aim of which was to decrease the exposure of scientists and others working with animals to airborne allergens) and also with a series of lectures designed to focus awareness on the problem. It is not, however, possible to conclude that the reduction in incidence of ALA is due simply to the lowered exposure to the allergen as no environmental monitoring was carried out. Attempts to rectify this omission are now being made. It is unlikely that the appearance of allergic symptoms has merely been delayed by the precautionary measures because, as table 1 suggests, the improvement was maintained for up to three years of exposure.

The vexed relation between ALA and atopy has become a little clearer from the results of this study. It appears that at least during the first year, most of those with symptoms due to animals are also atopic as shown by skin tests to either grass pollen or house dust mite. It must be emphasised, however, that the reverse does not hold good. Most atopic subjects do not develop ALA during their first year of contact. This latter finding is particularly relevant to those institutions whose recruitment policy forbids the employment of atopic individuals to work with animals. Furthermore, the positive correlation apparent during the first year is not maintained during the second and third years. The importance of atopy in determining the nature and severity of the symptoms was not carried out; in any case most of the symptomatic individuals were atopic during the first year and the numbers becoming symptomatic in the two succeeding years of the 1982 cohorts were small. This matter will be dealt with in more detail in a subsequent communication.

The tests of IgE antibody (either by skin test or by estimation of specific circulating antibody-and in general, these two estimates gave the same result) disclosed a complex situation. After one year of exposure, between $40 \%$ and $64 \%$ of symptomatic subjects in the 1982-4 cohorts had IgE antibody to rat urine allergen. If antibody to other animal allergens was included the correlation rose to $70-86 \%$ but many of these other antibodies were to species other than those reported as being responsible for the symptoms. Further evidence of complexity was seen when the detailed results from selected individuals of the 1982 cohort were analysed (again, this will be detailed in a subsequent communication). Many different patterns of response were seen. High levels of circulating (specific) IgE antibody do not necessarily indicate severe, or indeed occasionally, any, allergy developing during the first three years. Possibly the appropriate source of allergen was not used, either because it was not present in the preparation or was from a source (saliva, for example) not represented. At present tests for antibody appear to be of value as an aid to diagnosis but they do not replace careful clinical evaluation.

That rats are a common cause of allergy is confirmed by the results shown in table 2 . Although rats are the most commonly used species in this establishment this does not, in our judgement, fully account for their allergenicity since large numbers of the other species are also used. The absence of reports of allergy to guinea pigs during the first year was surprising; they do, however, figure in the reports of subsequent years and this matter of responsible species will again be taken up in a later communication. The sites affected were more or less as expected, nasal symptoms being the commonest followed by skin, eyes, and chest. The severity of the symptoms was usually mild or moderate. Although some severe reactions were reported, they resulted in only four of the 383 individuals in this survey transferring to jobs where there was no exposure to animals.

The results and conclusions presented in this paper are concerned with a prospective study of ALA only during the first years of contact with animals and cannot be compared with studies derived from a cross section of individuals at a given time. One of our major objectives was to identify early those likely to become allergic to animals. Not surprisingly, this was not fully achieved. Although most of those who developed allergy during the first year were atopic, many of them never developed ALA, and during the second and third years an increasing proportion of non-atopic subjects became allergic to animals. Tests for IgE antibody are of great theoretical interest but, at present, they do not do more than aid diagnosis. Attempts to include the nature and frequency of contact with animals as additional indicators of those individuals likely to develop ALA were frustrated by the numerous types of procedures used and the impossibility of obtaining an accurate record of exposure. We expect that our current studies on monitoring exposure to allergen will provide more useful information.

We thank Sister D A Phillips for administering the questionnaires and for performing the skin tests and Mrs A V Thompson for her skilled technical help. We also acknowledge the help of the epidemiology unit, ICI, and the statistics group, Central Toxicology Laboratory, ICI, with the analyses.

\section{References}

1 Lincoln TA, Bolton NE, Garrett AS. Occupational allergy to 
animal dander and sera. J Occup Med 1974;16:465-9.

2 Lutsky II, Neuman I. Laboratory animal dander allergy: I. An occupational disease. Ann Allergy 1975;35:201-5.

3 Taylor G, Davies GE, Altounyan REC, et al. Allergic reactions to laboratory animals. Nature 1976;260:230.

4 Lutsky I, Toshner D. A review of allergic respiratory disease in laboratory animal workers. Lab Anim Sci 1978;28:751-6.

5 Gross NJ. Allergy to laboratory animals: epidemiologic, clinical, and physiologic aspects, and a trial of cromolyn in its management. J Allergy Clin Immunol 1980;66:158-65.

6 Cockcroft A, Edwards J, McCarthy P, Andersson N. Allergy in laboratory animal workers. Lancet 1981;ii:827-30.

7 Slovak AJM, Hill RN. Laboratory animal allergy: a clinical survey of an exposed population. Br J Ind Med 1981;38:38-41.

8 Davies GE, McArdle LA. Allergy to laboratory animals: a survey by questionnaire. Int Arch Allergy Appl Immunol 1981;64: 302-7.

9 Newman-Taylor AJ, Myers JR, Longbottom JL, Spackman D, Slovak AJM. Immunological differences between asthma and other allergic reactions in laboratory animal workers. Thor 1981;36:229.

10 Orr R, quoted by Dewdney JM. Allergy induced by exposure.f animals. Journal of the Royal Society of Medicine 1981; 928-32.

11 Lutsky I, Kalbfleisch JH, Fink JN. Occupational allergy to laboratory animals: employer practices. J Occup $M$ ged 1983;25:372-6.

12 Davies GE, Thompson AV, Niewola $Z$, et al. Allergy to laboratory animals: a retrospective and a prospective study. $\mathrm{Br} J$ Med 1983;40:442-9.

13 Agrup G, Belin L, Sjostedt L, Skerfving S. Allergy to laboratớfy animals in laboratory technicians and animal keepers. $\mathrm{Br} J \mathrm{lg}$ Med 1986;43:192-8.

14 Davies GE, Thompson AV, Rackham M. Estimation of airborne rat-derived antigens by ELISA. J Immunoassay 1983;4:113-40

15 Ceska M, Eriksson R, Varga JM. Radioimmunosorbent assay allergens. J Allergy Clin Immunol 1972;49:1-9.

\section{Vancouver style}

All manuscripts submitted to the $\mathrm{Br} J$ Ind Med should conform to the uniform requirements for manuscripts submitted to biomedical journals (known as the Vancouver style)

The $\mathrm{Br} J$ Ind Med, together with many other international biomedical journals, has agreed to accept articles prepared in accordance with the Vancouver style. The style (described in full in $\mathrm{Br} \mathrm{Med} \mathrm{J,} 24$ February 1979, p 532) is intended to standardise requirements for authors.

References should be numbered consecutively in the order in which they are first mentioned in the text by Arabic numerals above the line on each occasion the reference is cited (Manson ${ }^{1}$ confirmed other reports ${ }^{2-5} \ldots$.. In future references to papers submitted to the $\mathrm{Br} J$ Ind Med should include: the names of all authors if there are six or less or, if there are more, the first thre followed by $e t$ al; the title of journal articles book chapters; the titles of journals abbreviated according to the style of Index Medicus; and the first and final page numbers of the article or chapter.

Examples of common forms of references are:

1 International Steering Committee of Medical Editors. Uniform requirements for manuscripts submitted to biomedical journals. Br Med J 1979;1:532-5.

2 Soter NA, Wasserman SI, Austen KF. Cold urticaria: release into the circulation of histamine and eosino-phil chemotactic factor of anaphylaxis during cold challenge. $N$ Engl J Med 1976;294:687-90.

3 Weinstein L, Swartz MN. Pathogenic properties of invading micro-organisms. In: Sodeman WA Jr, Sodeman WA, eds. Pathologic physiology: mechanisms of disease. Philadelphia: W B Saunders, 1974:457-72. 